\title{
Effects of bee propolis on thyroid function tests in healthy volunteers
}

\author{
Fawaz A Alassaf ${ }^{1 *}$, Mohannad E Qazzaz², Mohanad Alfahad ${ }^{3}$, Mohammed N \\ Abed $^{4}$, Mahmood HM Jasim ${ }^{4}$ and Imad A-J Thanoon ${ }^{5}$ \\ ${ }^{1}$ Department of Pharmacology and Toxicology, ${ }^{2}$ Department of Pharmacognosy and Medicinal Plants, ${ }^{3}$ Department of \\ Pharmaceutics, ${ }^{4}$ Department of Pharmaceutical Chemistry, ${ }^{5}$ Department of Pharmacology, University of Mosul, College of \\ Medicine, Mosul, Nineveh Province, Iraq
}

*For correspondence: Email: Fawaz.Alassaf@uomosul.edu.iq; Tel: +964-7502274465

\begin{abstract}
Purpose: The current study investigates the effects of bee propolis as a dietary supplement on thyroid function in healthy individuals.

Methods: Sixty-nine apparently healthy subjects of both genders aged between 25 and 45 years and had a body mass index in the range of $18.5-25 \mathrm{~kg} \mathrm{~m}^{-2}$ were enrolled in the study. The participants were divided into two groups, 34 volunteers treated with $1 \mathrm{gram}$ of bee propolis daily and the other 35 were on placebo pills for 2 months. Total triiodothyronine (TT3), total thyroxine (TT4) and ultra-sensitive thyroid stimulating hormone (USTSH) were measured in the two groups before and after treatment to assess thyroid function.

Results: The results showed a significant increase in body weight (from $73.4 \pm 7.2$ to $74.8 \pm 7.5 \mathrm{~kg}, \mathrm{p}<$ 0.05 ) and BMI (from $24.2 \pm 1.2$ to $24.7 \pm 1.5 \mathrm{~kg} \mathrm{~m}^{-2}, p<0.05$ ) with significantly decreased TT3 (from $2.17 \pm 0.07$ to $1.87 \pm 0.09 \mathrm{nmol} / \mathrm{L}, p<0.01$ ) in bee propolis-treated group, whereas TT4 and USTSH showed non-significant changes.

Conclusion: The results reveal a significant association of bee propolis supplementation with reduced TT3 levels in healthy subjects. The link may assist clinicians in monitoring the safety of bee propolis supplementation.
\end{abstract}

Keywords: Bee propolis, Thyroid stimulating hormone, triiodothyronine and thyroxine

\begin{abstract}
This is an Open Access article that uses a fund-ing model which does not charge readers or their institutions for access and distributed under the terms of the Creative Commons Attribution License (http://creativecommons.org/licenses/by/4.0) and the Budapest Open Access Initiative (http://www.budapestopenaccessinitiative.org/read), which permit unrestricted use, distribution, and reproduction in any medium, provided the original work is properly credited.

Tropical Journal of Pharmaceutical Research is indexed by Science Citation Index (SciSearch), Scopus, International Pharmaceutical Abstract, Chemical Abstracts, Embase, Index Copernicus, EBSCO, African Index Medicus, JournalSeek, Journal Citation Reports/Science Edition, Directory of Open Access Journals (DOAJ), African Journal Online, Bioline International, Open-J-Gate and Pharmacy Abstracts
\end{abstract}

\section{INTRODUCTION}

Bee propolis, also known as bee glue, is a natural viscous and adhesive material made from beeswax, bee's enzymes and saliva in addition to some materials from the plants in the bees environment [1]. Propolis is prepared and transformed by bees to seal the cells of honeycombs and protect against intruders [2]. The diversity of the plant species that grow around the beehive can affect the chemical composition of propolis. Furthermore, the chemical composition can vary depending on the illumination, seasonality and food availability during the formation of propolis [3]. 
Regardless of differences in composition, propolis has revealed distinct medicinal benefits and has been widely used in the nutritional and pharmaceutical industries as a supplement and therapeutic agent [4]. It showed biological effects including antibacterial, anti-inflammatory, antioxidant, antifungal, anticancer, and immune system regulatory functions $[5,6]$.

Recent studies have shown that the most important ingredients in propolis that are responsible for biological effects are phenols, flavonoids, and aromatic compounds. The first approval for the use of propolis was in drug stores in London in the $17^{\text {th }}$ century. Following that, propolis became one of the commonly used drugs throughout $17^{\text {th }}$ to $20^{\text {th }}$ centuries due to its beneficial effect as an antibacterial agent [1]. Nowadays, bee propolis is available in a wide range of pharmaceutical dosage forms such as mouthwash preparations, capsules, tablets, face cream, ointments, solutions, lotions and toothpaste.

There have been some reports of propolis activities on thyroid diseases from different parts of the globe. One of these studies was to evaluate the effects of propolis on the viability of thyroid cancer cells, which concluded that propolis has weak cytotoxic properties against thyroid cancer cells with insignificant decrease in the viability of normal thyroid cell line [7]. These interesting reports about the activity of propolis motivated this research team to study the effects of bee propolis on thyroid functions. In a previous study by the same team which evaluated effects of bee propolis on fasting blood glucose, glycosylated haemoglobin and insulin sensitivity in healthy subjects, an increase in body weight and BMI, as well as a decrease in FBG and $\mathrm{HbA1c}$ levels in healthy individuals were reported [8]. In the current study, the effects of bee propolis on thyroid function tests are reported to evaluate an additional aspect of its safety in healthy individuals.

\section{METHODS}

Ethically, this study followed the international standards and the 1975 Helsinki declarations and its subsequent revisions [9]. It was approved by the scientific committee in the College of Pharmacy, University of Mosul. Additionally, approval to conduct the study on human subjects was obtained from the Ethical Committee in Nineveh Health Directorate, which is a representative of the Iraqi Ministry of Health in the city of Mosul (approval no. 1050 in 2019). The expected outcomes of the study were discussed with the involved subjects before requesting them to sign an informed consent. From January $10^{\text {th }}$ to May $30^{\text {th }} 2019$, a convenient number of 79 healthy subjects of both genders, who had signed the consent forms, were enrolled in this study. The recruited eligible volunteers were aged between 25 and 45 years, with a BMl of $18.5-25 \mathrm{~kg} \mathrm{~m}^{-2}$. Participants with BMI of less than $18.5 \mathrm{~kg} \mathrm{~m}^{-2}$ or more than $25 \mathrm{~kg}$ $\mathrm{m}^{-2}$, those on nutritional supplements, with diseases or on any medications were excluded. Participants were divided into two groups; 39 volunteers were on placebo and the remaining 40 were on bee propolis supplements. Four subjects from the placebo group and six of the supplement group dropped out for the lack of compliance. All subjects from the supplement group were on a single daily dose of $1 \mathrm{gram}$ of bee propolis (Woods Supplements, UK) for 60 days. A 5-ml of blood sample was taken from the participants before and after the treatment between the hours of 8 a.m. and 11 a.m. following at least 8-hour fasting. For all tests, blood samples were collected at room temperature followed by centrifugation for $10 \mathrm{~min}$ and then serums were kept at $-20{ }^{\circ} \mathrm{C}$ before analysis. Thyroid function was evaluated by measuring total triiodothyronine (TT3), total thyroxine (TT4) and ultra-sensitive thyroid stimulating hormone (USTSH) using enzymelinked fluorescent assay (mini VIDAS ${ }^{\circ}$ bioMérieux).

\section{Data analysis}

All values were expressed as mean \pm standard deviation. Samples were statistically compared using Student's paired t-test for single data. Graph Pad Prism 8.0 software was used to determine whether there is a significant difference or not. $P<0.05$ was considered statistically significant.

\section{RESULTS}

A total of sixty-nine subjects were examined for thyroid function tests (T3 and T4) and TSH following 60-day administration of $1 \mathrm{~g}$ of bee propolis. Table 1 shows the personal characteristics of the study subjects at baseline and 2 months on placebo and bee propolis, indicating a significant increase in weight and $\mathrm{BMI}$ in volunteers on the nutritional supplements.

The T3, T4 and UTSH were measured at baseline and 2 months following bee propolis administration, as shown in Figure 1. The mean of TT3 significantly decreased from $2.17 \pm 0.07$ to $1.87 \pm 0.09(p<0.01)$ after consuming bee propolis for 2 months. 

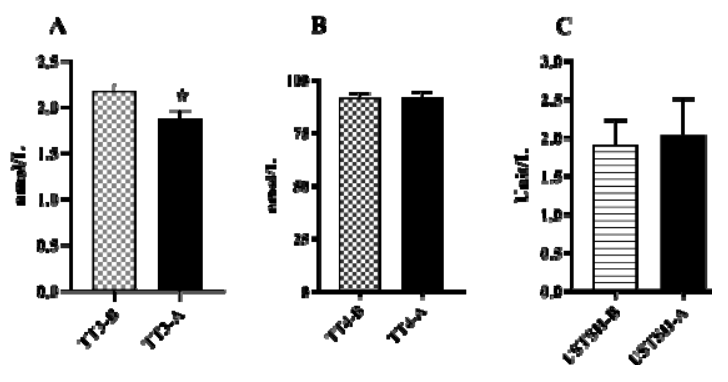

Figure 1: Comparison of the levels of serum thyroid hormones at baseline and 2 months following bee propolis administration. A: serum T3 levels, B: T4 levels and $\mathbf{C}$ : TSH levels. In each graph, the letters $B$ and $A$ following the hyphen on the $X$-axis represent the serum level of the corresponding hormone before and after bee propolis supplementation respectively. The results are statistically significant $\left({ }^{*} p<0.05\right)$ where indicated as measured by the paired t-test

The results of the placebo group were statically insignificant after 2 months for TT3 (from $2.20 \pm$ 0.36 to $2.22 \pm 0.37$ ), TT4 (from $90.81 \pm 9.76$ to $91.10 \pm 11.38$ ) and UTSH (from $2.05 \pm 0.31$ to $2.10 \pm 0.25)$ as shown in Figure 2.


Figure 2: Thyroid hormones levels at baseline and after 2 months in the propolis group compared to the placebo group. A: serum T3 levels, B: T4 levels and C: TSH levels. The letter $P$ in the hormone names on the $\mathrm{X}$-axis in the 3 graphs refers to the placebo group, while the letters $B$ and $A$ correspond to hormone levels before and after treatment with placebo or propolis respectively. The results are statistically significant $\left({ }^{*} p\right.$ $<0.05$ ) where indicated according to analysis by oneway ANOVA followed by Tukey's post hoc test

On the other hand, changes in TT4 and UTSH following bee propolis supplementation were not statistically significant (from $91.55 \pm 2.33$ to
$91.81 \pm 2.56$ for TT4 and from $1.90 \pm 0.32$ to $2.03 \pm 0.47$ for UTSH). Furthermore, nonsignificant changes in TT3 (from $2.20 \pm 0.06$ to $2.22 \pm 0.06$ ), TT4 (from $90.81 \pm 1.57$ to $91.10 \pm$ 1.93) and UTSH (from $2.21 \pm 0.31$ to $2.10 \pm 0.25$ ) were noticed in the placebo group.

\section{DISCUSSION}

The use of nutritional supplements, including bee propolis, has skyrocketed in the recent years. To the best of the authors' knowledge, this is the first study to evaluate the effects of bee propolis on thyroid hormones and TSH in healthy individuals. The present study showed that administration of bee propolis for 2 months was associated with a significant increase in body weight and $\mathrm{BMI}$ and a significant decrease in T3 levels. However, changes in serum T4 and TSH levels were not statistically significant. Thyroid glands produce hormones that regulate the metabolic processes, growth and many body functions [10].

Our research group previously reported a correlation between body weight and $\mathrm{BMI}$ and the administration of 1-gram bee propolis for 60 days. This correlation was argued in our previous study on bee propolis and the glycemic control. The potential mechanism of the increased body weight could be explained by increased volunteers' appetite or enhanced peripheral tissue glucose uptake [8].

Bee propolis is a rich source of flavonoids. Flavonoids are the active ingredient of major scientific interest with a variety of biological effects including antioxidant and antithyroid effects. Flavonoids such as chrysin, pinocembrin and galangin are present in propolis [11]. Several studies demonstrated that dietary flavonoids may interfere with thyroid hormones, and it has been found that flavonoids can decrease serum T3 [12-14].

In 2011, Mittal et al reported a modest but significant reduction in serum T3 following 12week supplementation with soy flavonoids [13].

Table 1: Personal characteristics at baseline and 2 months following placebo, bee propolis administration

\begin{tabular}{lcccc}
\hline Parameter & $\begin{array}{c}\text { Before placebo } \\
\text { intake }\end{array}$ & $\begin{array}{c}\text { After placebo } \\
\text { intake }\end{array}$ & $\begin{array}{c}\text { Before bee propolis } \\
\text { intake }\end{array}$ & $\begin{array}{c}\text { After bee propolis } \\
\text { intake }\end{array}$ \\
\hline $\begin{array}{l}\text { Number } \\
\text { (male/female) }\end{array}$ & $35(20 / 15)$ & $35(20 / 15)$ & $34(23 / 11)$ & $34(23 / 11)$ \\
$\begin{array}{l}\text { Mean age } \\
\text { (years) }\end{array}$ & $39.57 \pm 6.5$ & $39.57 \pm 6.5$ & $36.88 \pm 3.8$ & $36.88 \pm 3.8$ \\
Weight $(\mathrm{kg})$ & & & \\
BMI $\left(\mathrm{kg} / \mathrm{m}^{2}\right)$ & $69.14 \pm 7.25$ & $70.61 \pm 7.1$ & $73.4 \pm 7.2$ & $74.8 \pm 7.5^{*}$ \\
\hline *Statistically significant results $(p<0.05)$ as measured using paired t-test & $24.2 \pm 1.2$ & $24.7 \pm 1.5^{*}$ \\
\hline
\end{tabular}


However, other studies revealed non-significant changes in serum T3 levels; for example, Ishizuki et al elucidated that daily administration of 30 gram soybean for 1 or 3 months in healthy subjects was associated with an elevation of TSH levels but within normal range and unchanged thyroid hormones levels. Goiter (thyromegaly) was also reported in half of those who received soybeans for 3 months, but it disappeared 1 month after soybean cessation indicating a time-dependent effect [15]. In 2008, Hampl et al showed that 7-day human consumption of natural soybean was associated with a transient increase in TSH levels and they concluded that thyroid hormone was correlated with the basal level of flavonoids [16]. The precise interpretation for such differences in these studies' outcomes remains unclear; differences in the administered doses, composition of flavonoids or the duration of administrated supplements could be important contributing factors.

Some potential mechanisms for the interaction between flavonoids and thyroid gland may be implicated; flavonoids such as quercetin prevents iodotyrosine formation through the inhibition of enzyme thyroid peroxidase (TPO). The latter is an enzyme involved in the synthesis of thyroid hormones by oxidizing iodide ions and eventually leading to the formation of T3 and T4 [17], and thus holds iodination. Other flavonoids inactivate TPO by non-competitive inhibition of tyrosine iodination, suggesting increased TSH levels. Furthermore, another mechanism by which flavonoids can affect the metabolism of thyroid hormones is by the inhibition of type I-deiodinase enzyme activity [18].

It has been reported that the dietary phenolic compounds can inhibit the TPO activity with a lower potency than the antithyroid drugs propylthiouracil and methimazole [19]. However, the major biological activity of phenolic compounds is not fully understood and could be associated with their bioavailability that is affected by the physicochemical properties of the substances.

\section{Limitations of the study}

The short time-frame and the small sample size might be the main limitations of the present study. Therefore, larger samples with longer follow up period might be recommended for the future work and more confirmatory results. Based on the results from the current study, it is recommended that healthy individuals on long term supplementation of bee propolis are required to assess their thyroid function.

\section{CONCLUSION}

The current trend of using nutritional supplements among populations increased the requirement of extensive research in such field to address the safety of the supplements including bee propolis. Healthcare providers should consider the possibility of changes in thyroid hormones when recommending bee propolis supplements for patients with thyroid disease or those who are on medications that can affect thyroid function and in long-term healthy consumers of bee propolis.

\section{DECLARATIONS}

\section{Acknowledgement}

The authors acknowledge the support from the College of Pharmacy, University of Mosul, Mosul, Iraq.

\section{Conflict of interest}

No conflict of interest is associated with this work.

\section{Contribution of authors}

We declare that this work was done by the authors named in this article and all liabilities pertaining to claims relating to the content of this article will be borne by the authors. The corresponding author of this manuscript and the co-authors have contributed to all of the following: Conception and design of the study objective and the collection of data and its analysis and interpretation (Fawaz A. Alassaf, Mohannad E. Qazzaz). Drafting the article or revising it critically (Fawaz A. Alassaf, Mahmood H. M. Jasim and Imad A-J Thanoon). Final authorisation of the version to be sent to the journal (Mohanad Alfahad, Mohammed N. Abed). Approved to be held responsible for all aspects of the research in warranting that questions related to the accuracy or integrity of any part of this research are properly inspected and resolved (All authors).

\section{Open Access}

This is an Open Access article that uses a funding model which does not charge readers or their institutions for access and distributed under the terms of the Creative Commons Attribution License (http://creativecommons.org/licenses/by/ 4.0) and the Budapest Open Access Initiative (http://www.budapestopenaccessinitiative.org/rea 
d), which permit unrestricted use, distribution, and reproduction in any medium, provided the original work is properly credited.

\section{REFERENCES}

1. Samadi N, Mozaffari-Khosravi H, Rahmanian $M$, Askarishahi M. Effects of bee propolis supplementation on glycemic control, lipid profile and insulin resistance indices in patients with type 2 diabetes: a randomized, double-blind clinical trial. J Integr Med 2017; 15(2): 124134.

2. Burdock GA. Review of the biological properties and toxicity of bee propolis (propolis). Food Chem Toxicol 1998; 36(4): 347-363.

3. Toreti VC, Sato HH, Pastore GM, Park YK. Recent Progress of Propolis for Its Biological and Chemical Compositions and Its Botanical Origin. Evidence-Based Complement Altern Med 2013; 2013: 1-13.

4. Machado JL, Assunçao AKM, da Silva MCP, Reis AS dos, Costa GC, Arruda D de S, Rocha BA, Vaz MM de OL, Paes AM de A, Guerra RNM. Brazilian green propolis: anti-inflammatory property by an immunomodulatory activity. Evidence-Based Complement Altern Med 2012; 2012: 1-10.

5. Verma MK, Pandey RK, Khanna R, Agarwal J. The antimicrobial effectiveness of $25 \%$ propolis extract in root canal irrigation of primary teeth. J Indian Soc Pedod Prev Dent 2014; 32(2): 120.

6. Dota KFD, Consolaro MEL, Svidzinski TIE, Bruschi ML. Antifungal activity of Brazilian propolis microparticles against yeasts isolated from vulvovaginal candidiasis. Evidence-Based Complement Altern Med 2011; 2011: 1-8.

7. Gülçelik NE, Zeybek D, Kaymaz F, Gencay Ö, Salih B, Sorkun K, Usman A, Aşan E. Antitumor activity of propolis on differentiated cancer cell lines. Med Sci 2012; 1: 292-300.

8. Alassaf FA, Jasim MHM, Alfahad M, Qazzaz ME, Abed $M N$, Thanoon IA. Effects of bee propolis on FBG, HbA1c and insulin resistance in healthy volunteers. Turkish $J$ Pharm Sci 2020. doi:10.4274/tjps.galenos.2020.50024.

9. World Medical Association. World Medical Association Declaration of Helsinki: ethical principles for medical research involving human subjects. J Am Coll Dent 2013; 310(20): 2191-4.

10. Brent GA. Mechanisms of thyroid hormone action. J Clin Invest 2012; 122(9): 3035-3043.

11. Li A, Xuan H, Sun A, Liu R, Cui J. Preparative separation of polyphenols from water-soluble fraction of Chinese propolis using macroporous absorptive resin coupled with preparative high performance liquid chromatography. J Chromatogr B Anal Technol Biomed Life Sci 2016; 1012: 42-49.

12. Chandra AK, Mondal C, Sinha S, Chakraborty A, Pearce EN. Synergic actions of polyphenols and cyanogens of peanut seed coat (Arachis hypogaea) on cytological, biochemical and functional changes in thyroid. Indian $J$ Exp Biol 2015; 53: 143-151.

13. Mittal $N$, Hota $D$, Dutta $P$, Bhansali $A$, Suri V, Aggarwal $N$, Marwah RK, Chakrabarti A. Evaluation of effect of isoflavone on thyroid economy \& autoimmunity in oophorectomised women: A randomised, double-blind, placebo-controlled trial. Indian J Med Res 2011; 133(6): 633.

14. Panda S, Kar A. Antithyroid effects of naringin, hesperidin and rutin in I-T4 induced hyperthyroid rats: Possible mediation through $5^{\prime} \mathrm{DI}$ activity. Pharmacol Reports 2014; 66(6): 1092-1099.

15. Ishizuki Y, Hirooka Y, Murata Y, Togashi K. The effects on the thyroid gland of soybeans administered experimentally in healthy subjects. Nippon Naibunpi Gakkai zasshi 1991; 67(5): 622-629.

16. Hampl R, Ostatnikova D, Celec P, Putz Z, Lapcík O, Matucha $P$. Short-term effect of soy consumption on thyroid hormone levels and correlation with phytoestrogen level in healthy subjects. Endocr Regul 2008; 42(2 Pt 3): 53-61.

17. Carvalho DP, Dupuy C. Thyroid hormone biosynthesis and release. Mol Cell Endocrinol 2017; 458: 6-15.

18. de Souza dos Santos MC, Gonçalves CFL, Vaisman M, Ferreira ACF, de Carvalho DP. Impact of flavonoids on thyroid function. Food Chem Toxicol 2011; 49(10): 2495-2502.

19. Habza-Kowalska E, Kaczor AA, Żuk J, Matosiuk D, Gawlik-Dziki U. Thyroid Peroxidase Activity is Inhibited by Phenolic Compounds-Impact of Interaction. Molecules 2019; 24(15): 2766. 